\title{
Influence of water absorption on flexural strength and elastic modulus in several resinous teeth splinting materials
}

\author{
Bae-Young Park, Soo-Yeon Kim, Jin-Woo Kim, Se-Hee Park, Kyung-Mo Cho* \\ Department of Conservative Dentistry, College of Dentistry, Gangneung-Wonju National University School of Dentistry, \\ Gangneung, Republic of Korea
}

Purpose: The purpose of this study was to compare flexural strength and elastic modulus of several splinting materials dependent on water absorption. Materials and Methods: Three different materials; LightFix, G-FIX, G-aenial Universal Flo; were used in this study. Thirty rectangular bar specimens $(25 \times 2 \times 2 \mathrm{~mm})$ of each materials were prepared. Fifteen specimens of each materials were stored in $100 \%$ relative humidity atmosphere, $37^{\circ} \mathrm{C}$ for 24 hours. The other specimens were stored in distilled water, $37^{\circ} \mathrm{C}$ for 30 days. Flexural strength and elastic modulus were calculated using Universal testing machine. One-way ANOVA and Scheffe's post hoc test at $95 \%$ level of significance were used on all test results. Results: In LightFix, flexural strength and elastic modulus were significantly decreased after aging. In G-FIX, there was no significant change in flexural strength and elastic modulus after aging. In Gaenial Universal Flo, flexural strength was significantly decreased, but elastic modulus did not change significantly. Statistical analysis reveals that flexural strength and elastic modulus increased in the order of LightFix, G-FIX, G-aenial Flo in both 24 hours and 30 days. Conclusion: It could be deduced from this study that flexural strength and elastic modulus of some resins could be changed when it aged in oral environment. Thus this should be considered when choosing a resin to perform a resin-bonded splint. (J Dent Rehabil Appl Sci 2018;34(2):72-9)

Key words: aging; elastic modulus; flexural strength; splint; tooth mobility

\section{서론}

일반적으로 레진 기질과 무기질 필러, 커플링제로 구성 되는 치과용 복합 레진은 좋은 기계적 성질, 심미성, 빠른 중합, 용이한 조작성, 법랑질에의 접착 능력을 지녀 치면 열구전색, 접착제, 레진시멘트, 충전재 등 치과에서 다양 한 용도로 사용되고 있다. ${ }^{1,2}$

복합 레진은 동요치 고정에도 사용할 수 있으며 최근 에는 치아 고정을 위한 전용 제품도 개발되고 있다. 이는 짧은 술식 시간, 간편한 임상적 적용, 우수한 심미성을 지 니고 구강 위생에 유리하며 치아 삭제가 거의 필요하지

*Correspondence to: Kyung-Mo Cho

Professor, Department of Conservative Dentistry, College of Dentistry, Gangneung-Wonju National University, 7, Jukheon-gil, Gangneung, 25457, Republic of Korea

Tel: +82-33-640-3155, Fax: +82-33-640-3103, E-mail: drbozon@gwnu.ac.kr Received: January 16, 2018/Last Revision: March 27, 2018/Accepted: April 22, 2018
않아 보존적이라는 면에서 장점을 지닌다. ${ }^{3}$

동요치 고정에 사용되는 레진은 치아의 생리적인 움직 임을 허용하는 낮은 탄성계수가 요구된다. 그 이유는 치 아고정 재료가 유연하면 어느 정도의 변형에도 파절이 되지 않지만 과도하게 단단하면 응력내구성이 적어 약화 가 점진적으로 진행되기 쉽기 때문이다. ${ }^{4}$

또한 레진계 치아고정 재료를 이용하여 동요치를 고정 할 때 인접치의 법랑질에 직접 재료를 접착시켜 사용하 기 때문에 법랑질에의 믿을만한 접착 강도를 지녀야 한 다. 그리고 구강내의 수복물은 저작압에 노출되고 온습 한 환경을 견뎌야 하기 때문에 높은 강도가 요구된다. ${ }^{3}$ 
이러한 요구를 충족하더라도 복합 레진이 구강 환경에 노출되면 시간이 지날수록 분해와 부식에 의해 변화를 겪는다는 점을 고려해야 한다. ${ }^{5}$ 이는 연하와 저작과 연관 된 스트레스에 의한 화학적 파괴, 수용성 구성요소의 침 출에 의한 화학적 조성변화, 크랙을 야기하는 침전과 팽 창현상, 계면에서의 누출, 부식에 의한 강도 소실, 가수분 해 등을 포함한다. ${ }^{5-9}$

특히 레진의 수분 흡수는 미반응 모노머, 모노머의 불 순물, 부가재, 분해산물의 방출과 필러 이온의 침출과 같 은 부정적인 영향을 야기하고 인장강도, 굴곡강도, 탄성 계수, 마모저항성과 같은 물리적, 기계적 성질에 부정적 인 영향을 미친다. ${ }^{10-12}$ 수분 흡수가 레진에 영향을 미치는 이유는 두가지가 있는데 이는 가수분해와 가소화 작용이 다. ${ }^{13}$ 가수분해는 수분 흡수시 실란과 필러 입자 사이의 접착이 분해돼 궁극적으로 필러-레진기질의 탈착을 야기 한다는 것인데 ${ }^{1,13}$ 이는 확산속도의존적 과정으로 중합종 류, 필러 종류, 필러 입자의 표면처리에 의해 영향을 받는 다. ${ }^{14}$ 가소화 작용은 수분이 중합체의 네트워크를 팽창시 키고 체인 사이의 마찰력을 감소시키는 작용을 통해 중 합체 구성요소의 연화가 된다는 것이다. ${ }^{13,14}$

따라서 동요치 고정에 사용되는 여러 레진 재료들이 에이징을 겪은 후 어떤 물리적 성질의 변화를 보이는지가 임상적으로 중요하나 이에 대한 연구는 부족하며 특히 최근에 시판됐거나 시판 준비 중인 제품에 관한 연구는 거의 없다.

이에 본 연구에서는 동요치 고정에 사용되는 여러 광 중합형 레진계 치아고정 재료의 에이징에 따른 굴곡강도 와 탄성계수를 비교해 물리적 성질에 대한 정보를 제공, 임상가들이 재료를 선택하는 데에 도움이 되고자 했다.

\section{연구 재료 및 방법}

\section{1. 실험 재료}

실험군으로 3종의 레진을 사용했다. 광중합 동요치 고 정 재료인 LightFix (Sun Medical Co., Shiga, Japan), GFIX (GC Co., Tokyo, Japan), 치아고정 재료로 사용 가 능한 흐름성 복합 레진인 G-aenial Universal Flo shade A2 (GC Co.)를 사용했다. 각 재료의 구성성분은 Table 1 에 나타냈다.

\section{1) 시편 제작}

가로 $25 \mathrm{~mm}$, 세로 $2 \mathrm{~mm}$, 높이 $2 \mathrm{~mm}$ 의 홈을 파놓은 스테인리스강 재질의 주형(Fig. 1)을 이용해 각 실험군 당 30 개씩 총 90 개의 시편을 제작했다. 주형을 조립한 상 태에서 홈에 각 재료를 유입시키고 celluloid matrix를 압접하고 슬라이드 글라스로 압력을 주어 균일한 두께 가 되도록 한 후 중합했다. $\mathrm{LED}$ 를 이용한 광중합기인 G-Light (GC Co.)를 이용해 다른 위치에서 3회 중첩되게 20 초씩 중합을 완료한 후 주형을 분리해 시편을 주형에 서 제거했다. 상대습도 $100 \%, 37^{\circ} \mathrm{C}$ 항온기(SIB-1, Seo-

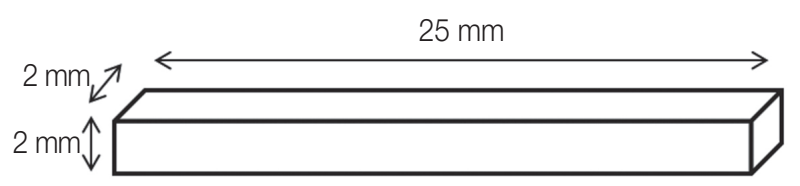

Fig. 1. Schematic drawing of specimen.

Table 1. Composition and shade of materials used in this study

\begin{tabular}{|c|c|c|c|}
\hline Material & Manufactures & Shade & Composition \\
\hline LightFix & Sun Medical & Clear & $\begin{array}{l}\text { Methacrylic acid ester (UDMA, 4-META, etc), acylic acid ester, } \\
\text { photo initiator }\end{array}$ \\
\hline G-FIX & GC & Clear & $\begin{array}{l}\text { Glass filler, methacrylic acid ester, phosphoric acid ester monomer, } \\
\text { photo initiator }\end{array}$ \\
\hline G-aenial Universal Flo & GC & A2 & 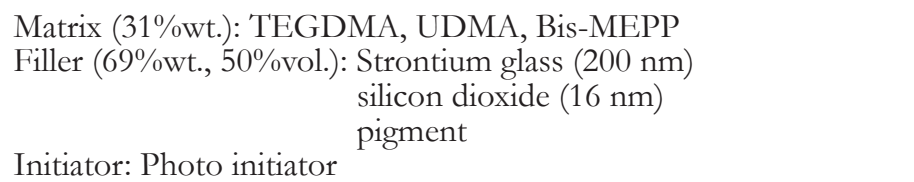 \\
\hline
\end{tabular}


kwang Science Co., Seoul, Korea)에서 각 실험군당 시편 15 개씩은 24 시간 동안 보관했고 나머지 시편은 $37^{\circ} \mathrm{C}$, 증 류수에 30 일간 보관했다. $0.01 \mathrm{~mm}$ 단위까지 측정 가능 한 디지털 캘리퍼(Mitutoyo CD-15CP, Kawasaki, Japan) 를 이용해 각각의 시편의 높이와 두께를 측정한 후 3점 굽힘 시험을 시행했다.

\section{2) 굴곡강도 및 탄성계수 측정}

만능시험기(RB-306, R\&B Inc., Daejeon, Korea)를 이 용해 분당 $1.0 \mathrm{~mm}$ 의 cross-head 속도, 최대하중 $800 \mathrm{~kg}$ 의 조건에서 시편이 파절되는 시점까지 하중을 줬다. 시 편에 가해진 최대 힘 $(\mathrm{N})$ 을 측정하고 기록했으며 굴곡강 도와 탄성계수는 다음 공식에 따라 계산했다.

$$
\text { 굴곡강도 } \mathrm{F}=3 \mathrm{P}_{\mathrm{f}} \mathrm{L} / 2 \mathrm{BH}^{2}(\mathrm{MPa})
$$

$\mathrm{B}$ 와 $\mathrm{H}$ 는 각각 시편의 폭과 두께 $(\mathrm{mm}), \mathrm{P}_{\mathrm{f}}$ 는 시편 파괴 시점의 최대 힘 $(\mathrm{N}), \mathrm{L}$ 은 지지대 사이의 간격 $(10 \mathrm{~mm})$ 이다.

$$
\text { 탄성계수 } \mathrm{E}=\delta_{f} / \delta_{y} \times \mathrm{L}^{3} / 4 \mathrm{BH}^{3}(\mathrm{GPa})
$$

$\mathrm{B}$ 와 $\mathrm{H}$ 는 각각 시편의 폭과 두께( $\mathrm{mm}$ 단위), $\mathrm{L}$ 은 지지 대 사이의 간격 $(10 \mathrm{~mm}), \delta_{f} / \delta_{j}$ 는 단위 변형률 $\left(\delta_{y}\right)$ 에 대한 응력의 변화율 $\left(\delta_{f}\right)$ 이다.

\section{3) 통계 분석}

각 실험 재료의 24 시간 군과 30 일 군 간 비교를 위해 Independant T-test를 이용했다. 측정된 각 실험 재료의 굴곡강도와 탄성계수는 One-way ANOVA test로 분석 했고 사후 검정으로 $95 \%$ 유의 수준에서 Scheffe's test를 이용했다.

\section{결과}

굴곡강도와 탄성계수의 평균과 표준편차, Independent T-test를 이용하여 알아본 각 실험 재료의 24시간 군과 30 일 군 사이의 유의성을 Table 2, 3에 나타냈다. Oneway ANOVA test 및 Scheffe's test를 시행해 통계적 유 의성을 알아본 결과를 Fig. 2, 3에 나타냈다.

본 연구의 결과 LighFix군에서는 에이징 후에 굴곡강 도와 탄성계수가 유의하게 감소했다. 반면 G-FIX군에 서는 에이징 후에 굴곡강도와 탄성계수에 유의한 차이 가 없었다. G-aenial Universal Flo군에서는 굴곡강도는 유의하게 감소했으나 탄성계수는 유의한 변화가 없었다. 한편 굴곡강도와 탄성계수는 24 시간 군, 30 일 군 모두 G-aenial Universal Flo가 유의하게 가장 컸고 LightFix 가 유의하게 가장 작았다.

Table 2. Flexural strength of tested materials [Mean (MPa) and Standard deviation]

\begin{tabular}{cccc}
\hline Group & \multicolumn{2}{c}{ Mean $(\mathrm{MPa}) \pm$ Standard deviation } & 30 days \\
& 24 hours & Significance \\
\hline LightFix & $66.9 \pm 3.4$ & $38.3 \pm 4.3$ & $*$ \\
G-FIX & $72.4 \pm 3.9$ & $72.3 \pm 9.7$ & $*$ \\
G-aenial Universal Flo & $112.3 \pm 6.7$ & $89.0 \pm 16.1$ & $*$ \\
\hline
\end{tabular}

*: Significant differences were detected in each materials (Independent T-test, $P<0.05$ ).

Table 3. Elastic modulus of tested materials [Mean (GPa) and Standard deviation]

\begin{tabular}{cccc}
\hline Group & \multicolumn{2}{c}{ Mean $(\mathrm{GPa}) \pm$ Standard deviation } & Significance \\
& 24 hours & 30 days & $*$ \\
LightFix & $28.5 \pm 5.5$ & $8.3 \pm 6.0$ & \\
G-FIX & $40.7 \pm 8.2$ & $38.0 \pm 5.6$ & \\
G-aenial Universal Flo & $101.7 \pm 9.5$ & $98.0 \pm 10.6$ & \\
\hline
\end{tabular}

*: Significant differences were detected in each materials (Independent T-test, $P<0.05$ ). 


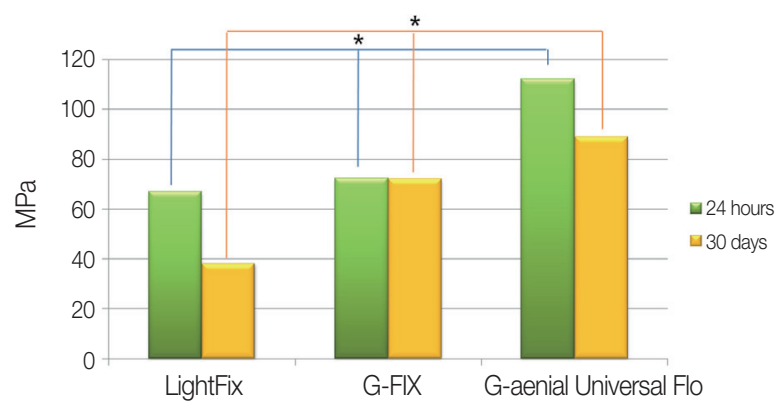

Fig. 2. Result of flexural strength (Scheffe's test).

*: Significant differences were detected $(P<0.05)$ in each materials.

\section{고찰}

ISO-4049 기준에 따르면, ${ }^{15}$ 3점 굽힘 시험시 지지대 사 이의 간격을 $20 \mathrm{~mm}$ 로 설정해야 하지만 이번 실험에서는 지지대 사이의 간격을 $10 \mathrm{~mm}$ 로 설정했다. 그 이유는 예 비 실험시 지지대 사이의 간격을 $20 \mathrm{~mm}$ 로 설정했을 때 LightFix의 파절이 일어나지 않아 측정이 불가했기 때문 이다.

LightFix 는 UDMA, 4-META를 포함하는 광중합형 레진계 치아고정 재료로 다른 실험 재료들에 비해 굴곡 강도와 탄성계수가 유의하게 낮았다. 복합 레진의 기계 적 성질은 모노머의 종류와 양, 변환의 정도, 무기질 필러 의 종류와 크기, 커플링제의 종류, 개시제의 양 등 레진의 조성과 연관된 많은 요소와 관련이 있다. ${ }^{16}$ 무기질 필러 입자들은 기질보다 강한 기계적 성질을 나타내므로 무기 질 필러의 함량이 높으면 레진은 높은 굴곡강도와 탄성 계수를 가진다. ${ }^{16,17}$ 이를 통해 LightFix가 다른 복합 레진 들에 비해 낮은 기계적 성질을 보이는 이유 중 하나는 무 기질 필러를 포함하지 않기 때문이라고 볼 수 있다. 이에 반해 G-aenial Universal Flo는 이산화규소, 스트론튬 글 라스 등의 무기질 필러를 $69 \%$ 중량비로 함유하는데 이 것은 비교적 높은 기계적 성질을 나타내는 이유 중 하나 가 될 수 있다.

어떤 연구에서 건조한 환경에서보다 습한 환경에서 레 진의 굴곡강도와 탄성계수가 감소했는데, ${ }^{18}$ 이는 이번 연 구에서 LightFix가 에이징시 굴곡강도와 탄성계수가 감 소한 것과 일치한다. 이를 통해 LightFix가 상대적으로 더 많은 수분 흡수를 했거나 수분 저항성 면에서 불리하 다고 볼 수 있다.

치과용 레진의 대다수는 무기질 필러의 첨가를 위해 희

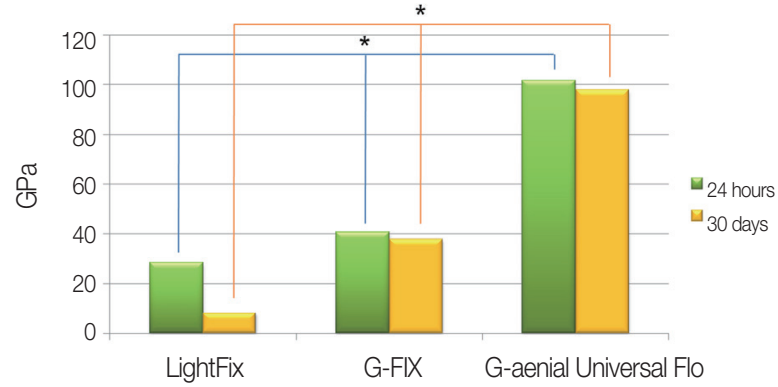

Fig. 3. Result of elastic modulus (Scheffe's test). *: Significant differences were detected $(P<0.05)$ in each materials.

석용 모노머가 필요하고, ${ }^{19,20}$ 일반적으로 Triethyleneglycoldimethacrylate (TEGDMA)가 사용되는데 이는 분 자량과 점도가 낮아 중합률을 높이지만 중합수축이 크 다. ${ }^{21-23}$ 따라서 Ethoxylated bisphenol-A dimethacrylate (Bis-EMA)와 같은 점도는 낮고 분자량은 큰 모노머가 최근 TEGDMA을 일부 또는 전부 대체하고 있다. ${ }^{24}$ 하지 만 Bis-EMA가 포함된 레진은 TEGDMA가 포함돼있는 레진보다 더 낮은 굴곡강도를 보인다는 연구가 있다. ${ }^{24}$ 그 이유는 TEGDMA가 더 효과적인 수소결합수용기를 가지고 Bis-EMA가 높은 분자량으로 인해 중합체의 가 교 결합 밀도를 감소시키며 이는 가소화 작용에 영향을 주기 때문이라고 했다. ${ }^{11,24,25}$ 어떤 논문에 따르면 G-FIX 는 Bis-EMA를 포함하는데, ${ }^{26}$ 이는 Bis-EMA를 포함하 는 G-FIX가 TEGDMA를 포함하는 G-aenial Universal Flo보다 굴곡강도가 낮은 이유를 일부 설명할 수 있다.

어떤 연구에 따르면 멸균 증류수는 레진의 압축강도에 장기간의 영향이 없었는데 저자는 그 이유를 수분으로 인한 복합 레진의 가수분해가 표본의 표층부에만 영향을 주기 때문이라고 분석했다. ${ }^{14}$ 이를 통해 본 연구에서 에이 징 후에도 G-FIX의 굴곡강도와 탄성계수가 유의한 변화 를 보이지 않은 이유를 일부 설명 가능할 수도 있다. 하지 만 G-FIX는 제조사에서 구성성분과 함량에 대한 자세 한 정보를 제공하지 않기 때문에 실험결과를 설명하기에 어려움이 있다. G-FIX 제조사에서 제공하는 설명에 따 르면 새롭게 개발한 고인성 모노머를 사용해 동요치 고 정에 적합한 유연성과 점인성을 부여했다고 하며 이를 설명하기 위해서는 추가적인 연구와 정보가 필요하다. ${ }^{3}$

어떤 연구에서 여러 복합 레진을 인공타액, 멸균증류 수, 에탄올을 이용하여 에이징했을 때 바륨과 스트론튬 의 침출이 관찰됐다고 했고 이는 용액이 레진의 이온 소 
실을 가속화시키는 이온 교환제로 작용하고 용액 침투 가 레진 기질의 용해와 입자 소실을 야기하며 기질의 이 온을 운반하기 때문이라고 설명했다. ${ }^{5}$ 이를 통해 수분이 G-aenial Universal Flo의 레진 기질의 용해와 스트론튬 의 소실을 야기하여 굴곡강도 감소에 일부 영향을 짔을 수 있다고 추측할 수 있다. 하지만 스트론튬 이온이 바륨 이온보다 직경이 더 작기 때문에 더 잘 확산되고 실리콘 이온도 방출이 잘된다고 한 어떤 연구에서는 이온 방출 과 굴곡강도, 탄성계수와의 관계는 적다고 했다. ${ }^{27}$ 그 이 유는 레진의 분해는 글라스 필러보다 약한 연결을 하는 레진 기질과 더 연관성이 있기 때문이라고 했다. ${ }^{27}$ 따라서 이온 방출이 본 실험의 연구결과에 영향을 줬는지는 알 수 없다.

마찬가지로 TEGDMA는 분자가 작아 수분 흡수시 더 많은 용출을 할 수 있다는 연구가 있지만, ${ }^{28,29} \mathrm{G}$-aenial Universal Flo에 포함돼있는 TEGDMA의 용출이 에이 징시 굴곡강도 감소에 영향을 쥤는지는 알 수 없다.

G-aenial Universal Flo의 탄성계수는 변하지 않았지만 굴곡강도는 유의하게 감소한 점을 동시에 명확하게 설명 하기 힘들다. 이는 모노머의 종류가 반응성, 점도, 중합수 축, 기계적 성질, 수분흡수, 수분에 의한 팽창과 강한 연 관이 있고, ${ }^{30}$ 필러, 모노머 그리고 커플링제의 종류, 함량 등에 의한 영향이 복합적으로 작용해 실험 결과에 나타 나기 때문으로 생각된다.

이번 연구에서 에이징시 굴곡강도와 탄성계수의 유의 한 감소를 나타낸 LightFix는 장기간의 동요치 고정에 사 용하기에는 적절하지 않다는 점이 임상적으로 의미가 있 다. 하지만 낮은 탄성계수를 보인다는 점에서 외상으로 인해 생긴 동요치의 고정이 단기간으로 필요한 경우 또 는 치주 질환으로 인해 비생리적인 동요가 생겼지만 치 주치료 후에 안정이 되기까지 단기간으로 고정시킬 목적 이라면 임상적으로 유용하게 사용할 수 있을 것으로 사 료되나 다양한 고정 기간에 따른 추가적인 연구가 더 필 요하다.

G-FIX의 경우 24 시간 군, 30 일 군 모두 LightFix보다 높은 굴곡강도, G-aenial Universal Flo보다 낮은 탄성계 수를 보이고 에이징 후에도 굴곡강도와 탄성계수의 유의 한 차이가 나타나지 않아 단기간, 장기간의 동요치 고정 에 적절할 것으로 생각된다.

에이징시 굴곡강도의 유의한 감소를 나타낸 G-aenial Universal Flo는 에이징 후에도 높은 굴곡강도를 보이지 만, 24 시간 군, 30 일 군 모두 탄성계수가 유의하게 높기
때문에 다른 재료에 비해 치아의 생리적인 동요를 허용 하지 않을 것으로 사료된다.

치아고정 재료의 선택시 고려되는 성질은 이번 연구에 서 조사한 굴곡강도와 탄성계수 뿐 아니라 심미성, 용해 도, 조작성, 생체적합성, 중합 수축, 법랑질과의 접착강 도, 인장강도, 마모저항성 등 다양한 물리적, 기계적 성질 및 다양한 요소가 복합적으로 고려돼야 한다.

또한 레진의 구강 내의 분해 과정에 연관된 메커니즘은 수분흡수와 관련된 가수분해, 가소화 작용만 관여하는 것이 아니라 교합과정, 온도, 화학적 분해, 효소, 단백질, 세균, 다양한 화학 물질, 생물학적 요소 등이 연관되어 상 당히 더 복잡하다. ${ }^{14}$ 그러므로 이러한 새로운 재료들의 성능에 대한 in vitro 연구가 더 필요하다.

\section{결론}

3점 굽힘 시험을 통해 치아 고정에 사용할 수 있는 여 러 레진의 굴곡강도와 탄성계수를 알아봤고 이에 대한 결과는 다음과 같다.

1. LightFix는 에이징 후에 굴곡강도와 탄성계수가 유 의하게 감소했으나 G-FIX는 유의한 차이가 없었고 G-aenial Universal Flo는 굴곡강도는 유의하게 감 소했으나 탄성계수는 유의한 차이가 없었다.

2. 굴곡강도와 탄성계수는 24 시간 군, 30 일 군 모두

G-aenial Universal Flo, G-FIX, LightFix 순으로 유 의하게 컸다.

이상의 결과를 바탕으로 G-FIX는 굴곡강도와 탄성계 수에 있어 에이징의 영향을 덜 받는다고 간주할 수 있으 며 비교적 높은 굴곡강도와 낮은 탄성계수를 가져 동요 치 고정에 유리할 것으로 생각된다.

LightFix는 다른 재료에 비해 탄성계수가 낮아 유연하 고 에이징 후에 더 탄성계수가 낮아진다는 장점이 있다. 하지만 에이징 후에 굴곡강도 또한 낮아지고 에이징의 영향을 상대적으로 많이 받으므로 단기간의 동요치 고정 에 적절할 것으로 생각된다.

G-aenial Universal Flo는 탄성계수가 비교적 높아 치 아의 생리적인 동요를 허용하지 않을 것으로 사료된다.

\section{Acknowledgements}

이 논문은 2017년도 강릉원주대학교 학술연구조성비 지원에 의하여 수행되었다. 


\section{ORCID}

Bae-Young Park https://orcid.org/0000-0002-8122-3091

Soo-Yeon Kim http://orcid.org/0000-0001-7437-6877

Jin-Woo Kim https://orcid.org/0000-0002-0004-0710

Se-Hee Park https://orcid.org/0000-0002-4052-4082

Kyung-Mo Cho https://orcid.org/0000-0003-3464-9425

\section{References}

1. Zhang $\mathrm{Y}, \mathrm{Xu}$ J. Effect of immersion in various media on the sorption, solubility, elution of unreacted monomers, and flexural properties of two model dental composite compositions. J Mater Sci Mater Med 2008;19:2477-83.

2. Sideridou ID, Achilias DS. Elution study of unreacted Bis-GMA, TEGDMA, UDMA, and BisEMA from light-cured dental resins and resin composites using HPLC. J Biomed Mater Res B Appl Biomater 2005;74:617-26.

3. Yoo JI, Kim SY, Batbayar B, Kim JW, Park SH, Cho KM. Comparison of flexural strength and modulus of elasticity in several resinous teeth splinting materials. J Dent Rehabil Appl Sci 2016;32:169-75.

4. Mazzoleni S, Meschia G, Cortesi R, Bressan E, Tomasi C, Ferro R, Stellini E. In vitro comparison of the flexibility of different splint systems used in dental traumatology. Dent Traumatol 2010;26:30-6.

5. Zhou M, Drummond JL, Hanley L. Barium and strontium leaching from aged glass particle/resin matrix dental composites. Dent Mater 2005;21:14555.

6. Drummond JL. Cyclic fatigue of composite restorative materials. J Oral Rehabil 1989;16:509-20.

7. Drummond JL, Khalaf MA, Randolph RG. In vitro ageing of composite restorative materials. Clin Mater 1988;3:209-21.

8. Wu W, McKinney JE. Influence of chemicals on wear of dental composites. J Dent Res 1982;61: 1180-3.

9. Truong VT, Tyas MJ. Prediction of in vivo wear in posterior composite resins: a fracture mechanics approach. Dent Mater 1988;4:318-27.

10. Toledano M, Osorio R, Osorio E, Aguilera FS, Re- meo A, de la Higuera B, García-Godoy F. Sorption and solubility testing of orthodontic bonding cements in different solutions. J Biomed Mater Res B Appl Biomater 2006;76:251-6.

11. Sideridou I, Tserki V, Papanastasiou G. Study of water sorption, solubility and modulus of elasticity of light-cured dimethacrylate-based dental resins. Biomaterials 2003;24:655-65.

12. Asaoka K, Hirano S. Diffusion coefficient of water through dental composite resin. Biomaterials 2003;24:975-9.

13. Toledano M, Osorio R, Osorio E, Fuentes V, Prati C, García-Godoy F. Sorption and solubility of resin-based restorative dental materials. J Dent 2003; 31:43-50.

14. Da Fonte Porto Carreiro A, Dos Santos Cruz C, Vergani CE. Hardness and compressive strength of indirect composite resins: effects of immersion in distilled water. J Oral Rehabil 2004;31:1085-9.

15. International Organization for Standardization. Dentistry-Polymer-based restorative material. ISO 4049, 2009.

16. de Melo Monteiro GQ, Montes MA. Evaluation of linear polymerization shrinkage, flexural strength and modulus of elasticity of dental composites. Mat Res 2010;13:51-5.

17. Hofmann N, Papsthart G, Hugo B, Klaiber B. Comparison of photo-activation versus chemical or dual-curing of resin-based luting cements regarding flexural strength, modulus and surface hardness. J Oral Rehabil 2001;28:1022-8.

18. Oysaed H, Ruyter IE. Composites for use in posterior teeth: mechanical properties tested under dry and wet conditions. J Biomed Mater Res 1986;20:261-71.

19. Dickens SH, Stansbury JW, Choi KM, Floyd CJE. Photopolymerization kinetics of methacrylate dental resins. Macromolecules 2003;36:6043-53.

20. Rueggeberg FA. From vulcanite to vinyl, a history of resins in restorative dentistry. J Prosthet Dent 2002;87:364-79.

21. Atai M, Watts DC. A new kinetic model for the photopolymerization shrinkage-strain of dental composites and resin-monomers. Dent Mater 2006; 22:785-91. 
22. Floyd CJ, Dickens SH. Network structure of BisGMA-and UDMA-based resin systems. Dent Mater 2006;22:1143-9.

23. Dewaele M, Truffier-Boutry D, Devaux J, Leloup G. Volume contraction in photocured dental resins: the shrinkage-conversion relationship revisited. Dent Mater 2006;22:359-65.

24. Gonçalves F, Kawano Y, Pfeifer C, Stansbury JW, Braga RR. Influence of BisGMA, TEGDMA, and BisEMA contents on viscosity, conversion, and flexural strength of experimental resins and composites. Eur J Oral Sci 2009;117:442-6.

25. Cook WD, Moopnar M. Influence of chemical structure on the fracture behaviour of dimethacrylate composite resins. Biomaterials 1990;11:272-6.

26. Cekic-Nagas I, Egilmez F, Ergun G, Vallittu PK,
Lassila LVJ. Load-bearing capacity of novel resinbased fixed dental prosthesis materials. Dent Mater J 2018:37:49-58.

27. Drummond JL, Andronova K, Al-Turki LI, Slaughter LD. Leaching and mechanical properties characterization of dental composites. J Biomed Mater Res B Appl Biomater 2004;71:172-80.

28. Geurtsen W. Substances released from dental resin composites and glass ionomer cements. Eur J Oral Sci 1998;106:687-95.

29. Ferracane JL. Elution of leachable components from composites. J Oral Rehabil 1994;21:441-52.

30. Moszner N, Salz U. New developments of polymeric dental composites. Prog Polym Sci 2001;26: 535-76. 


\section{수분 흡수가 여러 레진계 치아고정 재료의 굴곡강도와 탄성계수에 미치는 영향}

\section{박배영, 김수연, 김진우, 박세희, 조경모*}

강릉원주대학교 치과대학 치과보존학교실

목적: 본 연구의 목적은 수분 흡수가 여러 레진계 치아고정 재료의 굴곡강도와 탄성계수를 미치는 영향을 비교함으로써 물리적 성질에 대한 정보를 제공하는 것이다.

연구 재료 및 방법: 치아고정에 사용하는 레진으로 LightFix, G-FIX, G-aenial Universal Flo를 이용했다. 가로 $25 \mathrm{~mm}$, 세로 $2 \mathrm{~mm}$, 높이 $2 \mathrm{~mm}$ 의 시편을 각 재료당 즉시용 15 개과 에이징용 15 개를 제작했다. 즉시용은 $37^{\circ} \mathrm{C}, 100 \%$ 상대습도 에 24 시간 동안 보관됐고 에이징용은 30 일 동안 $37^{\circ} \mathrm{C}$, 증류수에 보관했다. 만능시험기를 이용해 굴곡강도와 탄성계수를 측정했고 independent t-test를 이용해 각 실험 재료의 24시간 군과 30 일 군 간 비교를 했다. 실험재료 간의 비교는 oneway ANOVA test로 분석했고 95\% 유의 수준으로 Scheffe's test를 이용해 사후 검정했다.

결과: 본 연구의 결과 LighFix군에서는 에이징 후에 굴곡강도와 탄성계수가 유의하게 감소했고 G-FIX군에서는 에이징 후에 굴곡강도와 탄성계수에 유의한 차이가 없었다. G-aenial Universal Flo군에서는 굴곡강도는 유의하게 감소했으나 탄성계수는 유의한 변화가 없었다. 한편 굴곡강도와 탄성계수는 24시간 군, 30 일 군 모두 LightFix가 가장 낮은 수치, Gaenial Universal Flo가 가장 높은 수치를 보였다.

결론: 어떤 레진의 굴곡강도와 탄성계수는 구강환경에서 에이징시 변화할 수 있으므로 동요치 고정을 목적으로 레진을 선택할 때 이를 고려해야 한다.

(구강회복응용과학지 2018;34(2):72-9)

주요어: 에이징; 탄성계수; 굴곡강도; 고정; 치아 동요

*교신저자: 조경모

(25457) 강원도 강릉시 죽헌길 7 강릉원주대학교 치과대학 치과보존학교실

Tel: 033-640-3155 | Fax: 033-640-3103 | E-mail: drbozon@gwnu. ac. kr

접수일: 2018년 1월16일 | 수정일: 2018년 3월 27일 | 채택일: 2018년 4월 22일 